\title{
Influence of Waste Marble Powder and Waste Granite Powder on the Mechanical and Durability Performance of Concrete
}

\author{
Engr Shafi Ullah, Muhammad Rehan Shahid, Shadab Tariq, Ammad Ahmad Khan \\ Civil Engineering, The University of Lahore, Islamabad, Pakistan. \\ sxu79@case.edu,70064248@student.uol.edu.pk,70065570@student.uol.edu.pk
}

\begin{abstract}
Industries produces large amount of marble and granite waste powder. These wastes are of two types, one of them is wet form which is impure form because it mixes with soil. And the other one is in powder form which is the pure form of marble waste and granite waste. These wastes are dumped in to the open land which cause serious environmental issues such as land problem, water problem and other deterioration. We can use these wastes to overcome environmental issues. Moreover, we can use these wastes in concrete to reduce construction economy. Waste marble powder, when we use in concrete, gives us good result in mechanical and durability characteristic of concrete. We used marble powder and granite powder with limited replacement of cement at $0 \%, 5 \%, 10 \%$ to check the performance of concrete in its mechanical and durability characteristics. This thesis describes a detailed experimental study on concrete's tensile strength and compressive strength and concrete water absorption. Better outcomes were obtained at 5-10\% replacement of cement with these wastes. Concrete's durability and mechanical characteristics were improved by increasing waste granite with limited replacing of cement up to $10 \%$. Determined Results show that a little content of marble dust and waste granite powder with limited replacement of cement will lower construction economy, reduce the cement quantity and gives better results in compressive strength
\end{abstract}

\section{Keywords:}

Compressive Strength, Marble dust, Split Tensile Strength, Water Absorption, Waste Granite powder

\section{Introduction}

\subsection{Background Study}

All over the world most used material in construction industries are concrete. Concrete is mostly used and its target is strong and durable structure. For low-cost concrete manufacturing, it will be long lasting and defendable Jain, Sancheti, and Gupta (2020). It has been recorded that several waste marble powders are generated during quarrying process. If we use the marble dust and granite dust in concrete to better its characteristics also, we can reduce environmental pollution like water pollution sand pollution etc. Marble dust can use in the limited replacing with cement V. M. Sounthararajan and A. Sivakumar (2013). Marble dust with limited replacing of cement show result of concrete mechanical characteristics, determined that up to $75 \%$ are helpful for concrete and satisfy for production of concrete.

Marble Powder is used for beautiful lock and also some marble fill work in construction and it provides pleasant looks to building so it is almost everywhere used so its powder can be easily found. $10 \%$ marble with limited replacing of cement with most suitable with all durable and mechanical properties. Chemically, Marbles are crystalline rocks composed predominately of calcite, dolomite or serpentine minerals P. V. G. Pathan and P. M. G. Pathan (2014). We mix marble powder with cement or synthetic resins to make counters, building stones, sculptures, floors and many other things fir building's decoration. The concrete containing Diatomite to 5\% show only $3 \%$ increase in strength compared with the controlled sample while for the same percentage the compressive strength was increased up to $26 \%$ after 28 days S. U. Khaliq, K. Shahzada, B. Alam, F. Bilal, M. Zeb, and F. Akbar (2016). Some things were noticed if marble powder was added with partial replacement of cement, it did not affect the final setting time of concrete. We replace marble powder with partial replacement of cement for making high strength, the coarse and fine aggregate particles themselves must be strong, which are the main important constituents in concrete Williams .C, P, and Kala .T (2008) Soomro et al. (2021). Adding marble powder with partial replacement of cement to concrete is reduce shrinkage, and low-cost concrete Vijayalakshmi, Sekar, and Ganesh prabhu (2013). 


\section{Research Methodology}

Particle size base on ASTM C136 for fine and coarse aggregate, specific gravity for fine and coarse aggregate (SSD base), water absorption for coarse and fine aggregates and moisture content for both aggregates. Mix design for M-15 were prepared. ACI211.1-91 used for preparing of mix design. After preparation of mix design, M-15 concrete were made with desired quantity of cement with limited replacing of marble and granite powder, fine, coarse aggregate, and water for nine cubes of 150x150x150 mm3 for nine types mixes for 7, 14 and 28 days for concrete compressive strength were obtained. Same as for cylinder for tensile strength, M-15 concrete were made with desired quantity of cement with limited replacing of marble and granite powder, fine, coarse aggregate, and water for nine cubes of 150x300 mm3 for nine types mixes for 7, 14 and 28 days for concrete tensile strength were obtained. For water absorption, we put out our samples from water and measure its wet weight and put our sample in oven for 24 hours and measure its dry weight for calculate the water absorption. The cubes water samples divided into two parts for curing purposes. Cube Sample "A" were cured in fresh water and Cube sample "B" were cured in salt water Two curing tanks were prepared for salt water. These tanks contain $10 \mathrm{~g}$ sodium chloride per liter water and one tank for fresh water. After preparing our curing tank we demolded our samples and place in the fresh water and $\mathrm{NaCl}$ solution. Lastly, each cube was test using Universal Testing Machine (UTM) at curing time and compressive strength were recorded. Same as tensile strength, each cylinder was test using Universal Testing Machine (UTM) at curing time and tensile strength were recorded.

\subsection{Mix Design}

It is ingredients of proportion that produce workable concrete and it is suitable for durability and mechanical property of concrete at suitable cost. Concrete Quality: Concrete mix design are very useful to gain good strength, durable concrete, similar and impermeable structures deciding related ingredients proportions of concrete keep in mind fresh concrete are achievable. Cement Economy Utilization: High rate of cement design mix to secure cement amount and lower cement contentment and give results in low hydration heat and also gives low shrinkage cracks.

\subsection{Sieve Analysis}

In Pakistan construction industry, the method used for analysis of sieve and lab tests ASTM and BS and many more, we used these methods for distribution of aggregates.

\subsection{Fine and Coarse Aggregate sieve analysis}

Fine aggregates analysis for were determined by ASTM C136.

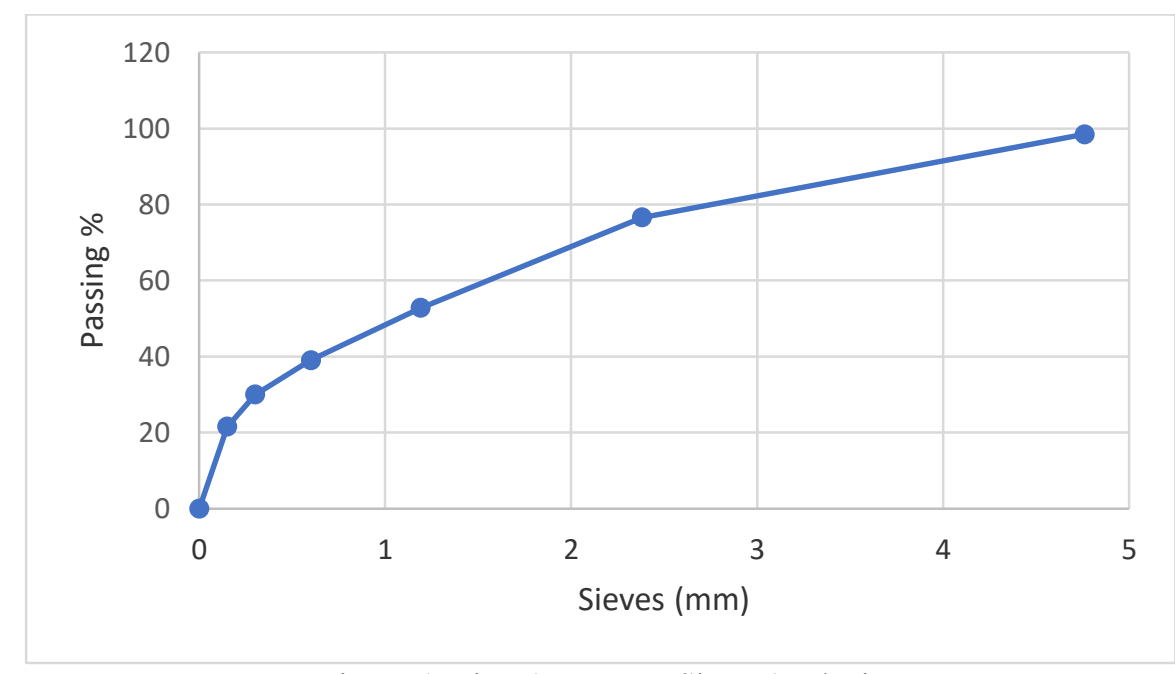

Figure 1. Fine Aggregate Sieve Analysis 


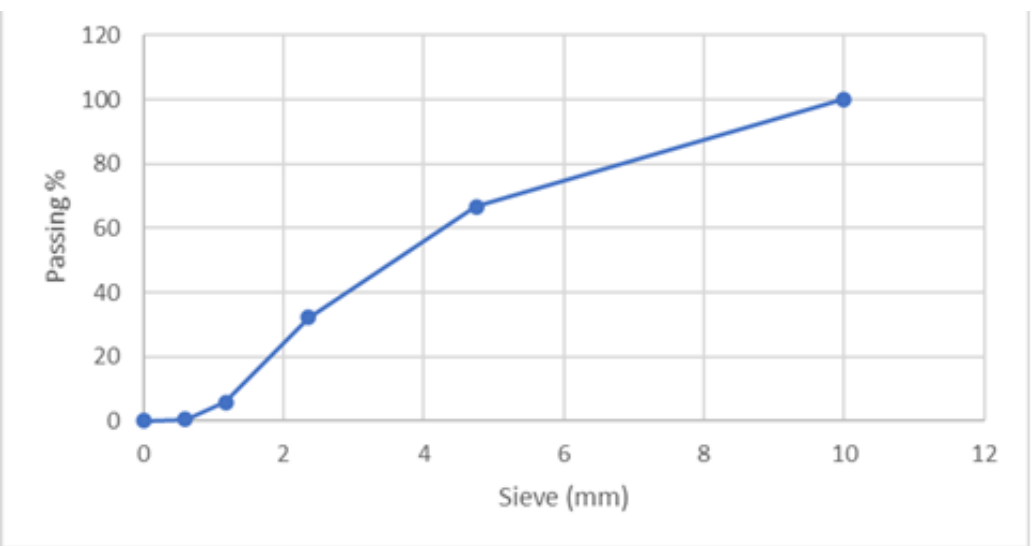

\subsection{Properties of Cement}

Figure 2. Coarse Aggregate Sieve analysis

The cement used in these experiments are (OPC) 53 Grade. Cement Soundness (IS: 4031) are 4mm (L2 = 12, L1 = 8). Consistency of Cement (ASTM C 187-98) are 30.9\%. The initial setting time were recorded are 92 minutes and the last setting time were recorded are $214 \mathrm{~min}$.

Table 1 Properties of Cement

$\begin{array}{cc}\text { Specific gravity of Fine Aggregate } & 2.62 \\ \text { Specific gravity of Coarse Aggregate } & 2.58 \\ \text { Water Absorption of Fine Aggregate } & 0.80 \\ \text { Water Absorption of Coarse Aggregate } & 4.406 \\ \text { Moisture Content of Fine aggregate } & 6.45 \\ \text { Moisture Content of Coarse aggregate } & 1.26\end{array}$

Table 2 Replacement levels

\begin{tabular}{ccc}
\hline Sr. No & GP & Replacement (\%) \\
& MP \\
\hline 1 & 0 & 0 \\
2 & 0 & 5 \\
3 & 0 & 10 \\
4 & 5 & 0 \\
5 & 10 & 0 \\
6 & 5 & 5 \\
7 & 5 & 10 \\
8 & 10 & 5 \\
9 & 10 & 10 \\
\hline
\end{tabular}

\subsection{Quantity of $\mathrm{NaCl}$ (sodium chloride) Used for curing purpose}

Concrete cubes mixes using in clean water also rehabilitate by use of clean water also concrete cube mixes by using salt water and cured in salt water. The quantity of salt for one liter of water are usual for mixing and curing purpose. We use 62.5 liters of water for curing in salt water. So, the quantity of salt used for curing for one sample is $69.44 \mathrm{~g}$.

Table 3 Quality of $\mathrm{NaCl}$ used for curing purpose

\begin{tabular}{cc}
\hline Concentration of $\mathrm{NaCl}$ salt $(\mathrm{g} / \mathrm{L})$ & Amount of salt used for curing $(\mathrm{g})$ \\
\hline 0 & 0 \\
10 & 625 \\
\hline
\end{tabular}

This work is licensed under a Creative Commons Attribution-ShareAlike 4.0 International License. 


\section{Results and Discussion}

\subsection{Results}

\subsection{Results for Compressive Strength BS 4550-3.4:1978}

The results for concrete compressive strength in addition of granite powder and marble dust with limited replacing of cement. Tables and graph are shown.

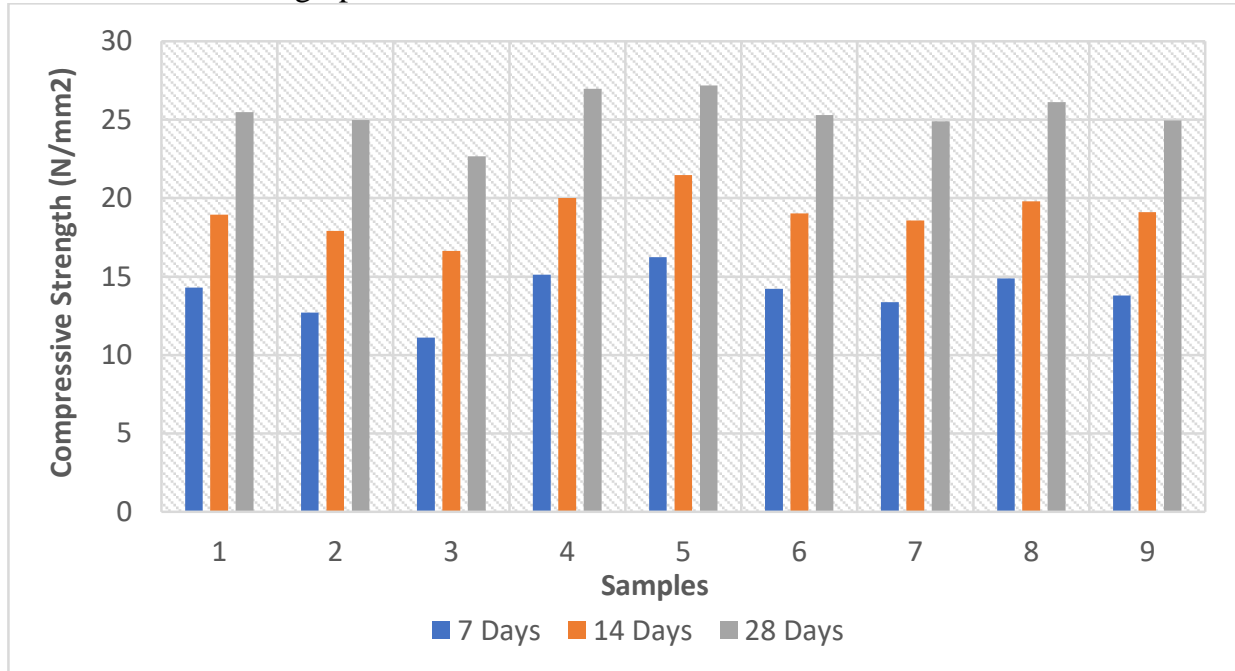

Figure 5. Results of Compressive Strength

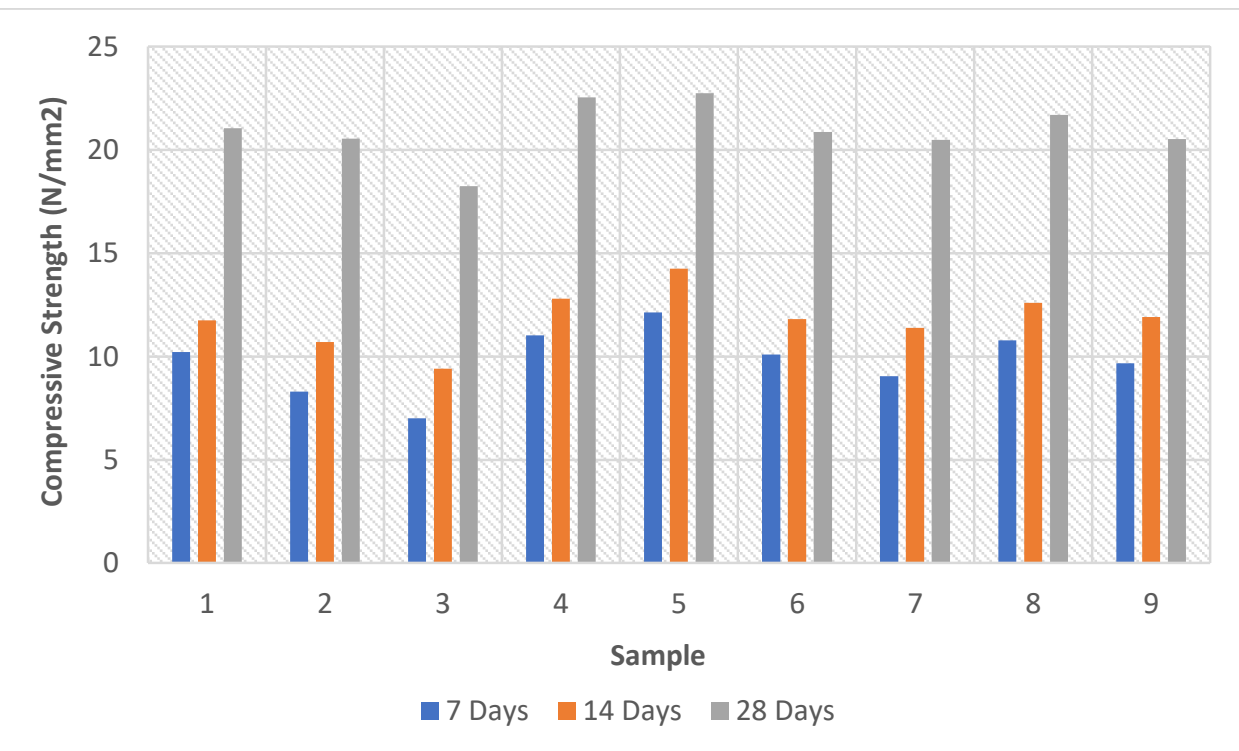

Figure 6. Results of Compressive Strength cured in $\mathrm{NaCl}$ Solution

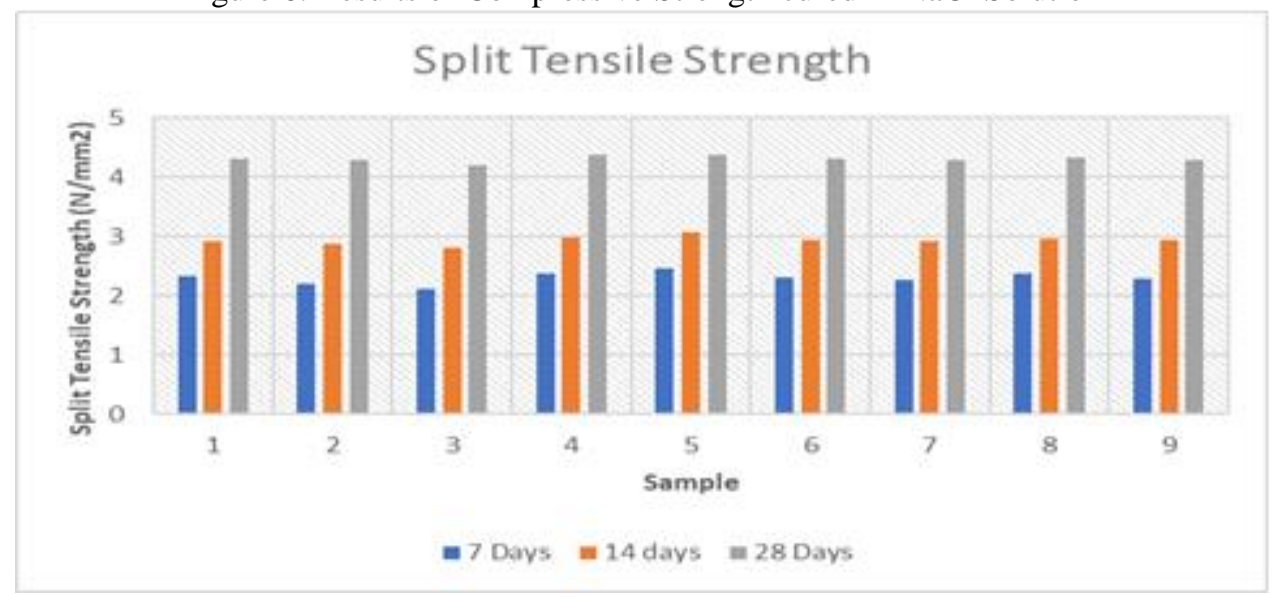

This work is licensed under a Creative Commons Attribution-ShareAlike 4.0 International License. 
Figure 7 Results for Split Tensile Strength

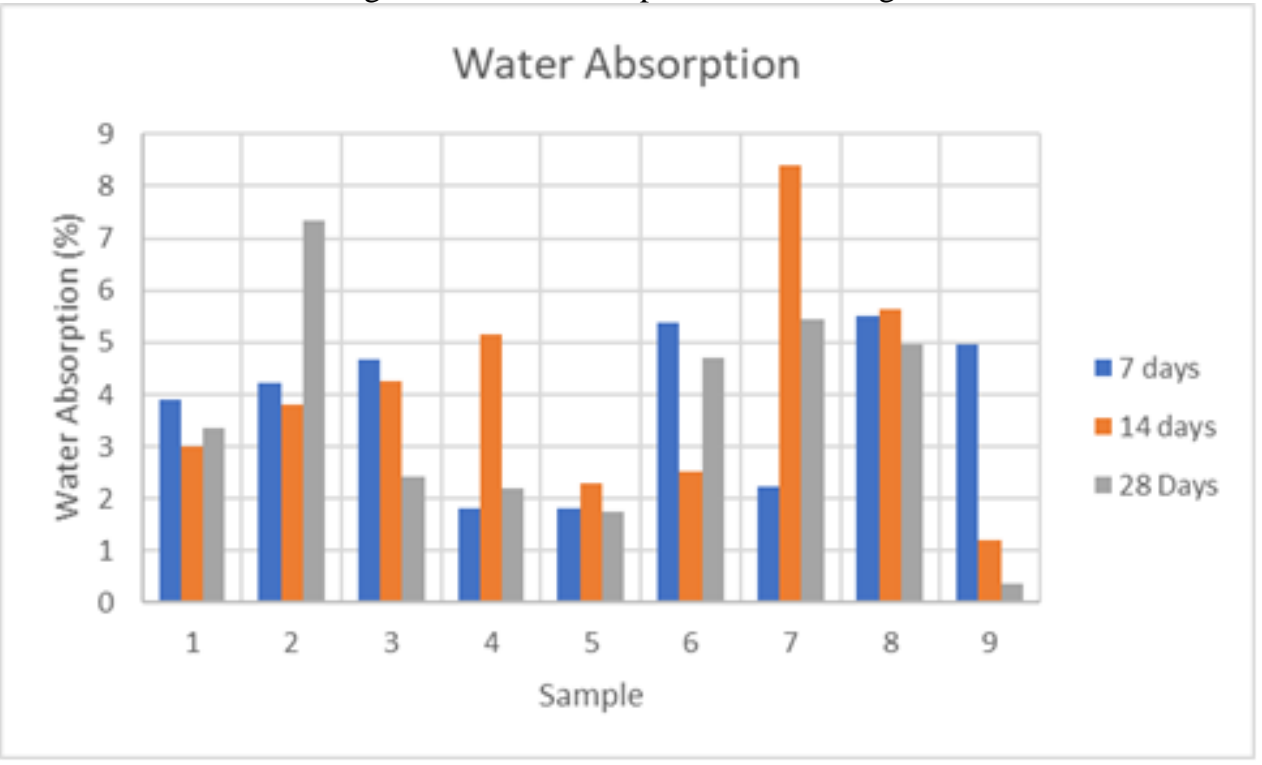

Figure 8 Results for Water Absorption

\subsection{Conclusion \& Recommendations}

Researchers have investigated the ideas on effect of the waste granite dust and waste marble dust with partial replacement of cement on concrete's compressive strength, concrete's compressive strength cure in $\mathrm{NaCl}$ solution, split tensile strength and water absorption of concrete. This research was conducted with different partial replacement of cement with waste granite dust and waste marble dust (0\%GP 0\%MP), (0\%GP 5\%MP), (0\%GP 10\%MP), (5\%GP 0\%MP), (10\%GP 0\%MP), (5\%GP 5\%MP), (5\%GP 10\%MP), (10\%GP 5\%MP), $(10 \% \mathrm{GP} 10 \% \mathrm{MP})$ and samples which were cured in $\mathrm{NaCl}$ solution at $\mathrm{NaCl}$ concentration 10 gram per litre. Concrete cubes were tested at 7, 14 and 28 days. The following conclusions are determined:

i. The concrete compressive strength which was cured in fresh water is higher than those samples which were cure in salt water.

j. Also, the concrete tensile strength with partial replacement of cement with granite dust $5 \%$ and $10 \%$ are higher than the other partial replacement of cement with marble dust and mixes of granite dust and marble dust at 7,14 and 28 days.

$\mathrm{k}$. The concrete compressive strength with replacement of cement with granite dust and waste marble dust (5\% GP 0\% MP), (10\%GP 0\%MP), (10\%GP 5\%MP\%) gives high compressive strength than the simple concrete and the other partial replacement with granite dust and marble dust at 7, 14 and 28 days.

1. At water absorption test partial replacement with granite dust at $5 \%$ and $10 \%$ gives low water absorption than ither partial replacement with cement at 7 days. So, similarly at 14 days, partial replacement with granite dust and marble dust (10\% GP $0 \% \mathrm{MP})$ and $(10 \% \mathrm{GP} 10 \% \mathrm{MP})$ gives low water absorption than the other partial replacement with cement. Similarly at 28 days, partial replacement of cement with granite dust and marble dust (5\%GP 0\%MP), (10\%GP 0\%MP) and (10\%GP $10 \% \mathrm{MP})$ gives very low water absorption than the others partial replacement of cement.

m. The salt water reduces the concrete strength because salt water has chlorides and sulphates.

\subsection{Acknowledgment}

Our primary thanks to Allah (subhanahuwata'ala) for health and energy, for giving us fortitude and perseverance, and for beautifying our lives with supportive colleagues throughout our time as bachelor students. We are glad Allah gave us means to recognize his presence in our lives and implement his final guidance. Our humble thanks to our parents for every imaginable kind of support and prayers. They supported us and took care of us through thick and continued to support us throughout in every part of our life. No words of us are enough to show our gratitude to them. We wished to express our deepest gratitude to our supervisor Engineer Shafi Ullah for his constructive criticism, support, and patience through thick and thin times in crafting this report. In the end we would like to thank all the individuals who provided emotional support and invaluable assistance during the study. 


\section{References}

Jain, Kishan Lal, Gaurav Sancheti, and Lalit Kumar Gupta. 2020. "Durability Performance of Waste Granite and Glass Powder Added Concrete." Construction and Building Materials 252:119075. doi: 10.1016/j.conbuildmat.2020.119075.

V. M. Sounthararajan and A. Sivakumar. 2013. "Effect of the Lime Content in Marble Powder for Producing High Strength Concrete,."” ARPN J. Eng. Appl. Sci., 8(4):260-264.

P. V. G. Pathan and P. M. G. Pathan. 2014. "“Feasibility and Need of Use of Waste Marble Powder in Concrete Production,." IOSR J. Mech. Civ. Eng. 1:23-26.

S. U. Khaliq, K. Shahzada, B. Alam, F. Bilal, M. Zeb, and F. Akbar. 2016. "“Marble Powder's Effect on Permeability and Mechanical Properties of Concrete,."” Int. J. Civ. Environ. Eng., 10(4):537-42.

Soomro, Bilawal, Sajjad Ali Mangi, Rashid Ali Bajkani, and Abdul Qudoos Junejo. 2021. "Recycling of Ceramic Tiles and Marble Powder Waste as Partial Substitution in Concrete." Neutron 20(2). doi: 10.29138/neutron.v21i1.88.

Vijayalakshmi, M., A. S. S. Sekar, and G. Ganesh prabhu. 2013. "Strength and Durability Properties of Concrete Made with Granite Industry Waste.” Construction and Building Materials 46:1-7. doi: 10.1016/j.conbuildmat.2013.04.018.

Williams .C, Kanmalai, Partheeban P, and Felix Kala .T. 2008. "Mechanical Properties Of High Performance Concrete Incorporating Granite Powder As Fine Aggregate.” International Journal on Design and Manufacturing Technologies 2(1):67-73. doi: 10.18000/ijodam.70029. 